\title{
Reporter Group
}

National Cancer Institute

\section{Source}

National Cancer Institute. Reporter Group. NCI Thesaurus. Code C44266.

Allows specification of the type of Reporter Design Element. (caMAGE) 